\title{
Estimating encounter location distributions from animal tracking data
}

\author{
Michael J. Noonan ${ }^{1,2}$ (D) | Ricardo Martinez-Garcia ${ }^{3}$ (D) | Grace H. Davis ${ }^{4,5,6,7,8}$ (D) | \\ Margaret C. Crofoot ${ }^{4,5,6,7,8}$ | Roland Kays ${ }^{9}$ (D) | Ben T. Hirsch ${ }^{5,10}$ (D) Damien Caillaud ${ }^{4}$ | \\ Eric Payne ${ }^{11}$ (D) | Andrew Sih ${ }^{11}$ (D) | David L. Sinn ${ }^{11}$ | Orr Spiegel ${ }^{12}$ (D) | \\ William F. Fagan ${ }^{13}$ (D) | Christen H. Fleming ${ }^{2,13}$ (D) | Justin M. Calabrese $2,13,14,15,16$ (i)
}

\begin{abstract}
${ }^{1}$ Department of Biology, The Irving K. Barber Faculty of Science, The University of British Columbia, Kelowna, BC, Canada; ${ }^{2}$ Smithsonian Conservation Biology Institute, National Zoological Park, Front Royal, VA, USA; ${ }^{3}$ ICTP South American Institute for Fundamental Research \& Instituto de Fisica Teorica - UNESP, Sao Paulo, Brazil; ${ }^{4}$ Department of Anthropology, University of California, Davis, CA, USA; ${ }^{5}$ Smithsonian Tropical Research Institute, Panama City, Panama; ${ }^{6}$ Department for the Ecology of Animal Societies, Max Planck Institute of Animal Behavior, Konstanz, Germany; ${ }^{7}$ Department of Biology, University of Konstanz, Konstanz, Germany; ${ }^{8}$ Centre for the Advanced Study of Collective Behaviour, University of Konstanz, Konstanz, Germany; ${ }^{9}$ North Carolina Museum of Natural Sciences and North Carolina State University, Raleigh, NC, USA; ${ }^{10}$ College of Science and Engineering, James Cook University, Townsville, Qld, Australia; ${ }^{11}$ Department of Environmental Science and Policy, University of California Davis, Davis, CA, USA; ${ }^{12}$ School of Zoology, Faculty of Life Sciences, Tel Aviv University, Tel Aviv, Israel; ${ }^{13}$ Department of Biology, University of Maryland, College Park, MD, USA; ${ }^{14}$ Center for Advanced Systems Understanding (CASUS), Görlitz, Germany; ${ }^{15}$ Helmholtz-Zentrum Dresden Rossendorf (HZDR), Dresden, Germany and ${ }^{16}$ Department of Ecological Modelling, Helmholtz Centre for Environmental Research (UFZ), Leipzig, Germany
\end{abstract}

\section{Correspondence}

Michael J. Noonan

Email: michael.noonan@ubc.ca

\section{Funding information}

Fundação de Amparo à Pesquisa do Estado de São Paulo, Grant/Award Number:

2016/01343-7, 2019/24433-0 and

2019/05523-8; Instituto Serrapilheira, Grant/Award Number: Serra-1911-31200; Smithsonian Institution; National Science Foundation, Grant/Award Number: NSF IIBR 1914928, N NSF IIBR 1915347 and NSFBCS 144755; Sächsisches Staatsministerium für Wissenschaft und Kunst; Germany's Federal Ministry of Education and Research; Center for the Advanced Study of Collective Behavior at the University of Konstanz, DFG Centre of Excellence 2117, Grant/Award Number: 422037984; Packard Foundation Fellowship, Grant/Award Number: 201665130

Handling Editor: Edward Codling

\section{Abstract}

1. Ecologists have long been interested in linking individual behaviour with higher level processes. For motile species, this 'upscaling' is governed by how well any given movement strategy maximizes encounters with positive factors and minimizes encounters with negative factors. Despite the importance of encounter events for a broad range of ecological processes, encounter theory has not kept pace with developments in animal tracking or movement modelling. Furthermore, existing work has focused primarily on the relationship between animal movement and encounter rates while the relationship between individual movement and the spatial locations of encounter events in the environment has remained conspicuously understudied.

2. Here, we bridge this gap by introducing a method for describing the long-term encounter location probabilities for movement within home ranges, termed the conditional distribution of encounters (CDE). We then derive this distribution, as well as confidence intervals, implement its statistical estimator into open-source software and demonstrate the broad ecological relevance of this distribution.

3. We first use simulated data to show how our estimator provides asymptotically consistent estimates. We then demonstrate the general utility of this method for three simulation-based scenarios that occur routinely in biological systems: (a) a population of individuals with home ranges that overlap with neighbours; (b) a

This is an open access article under the terms of the Creative Commons Attribution-NonCommercial License, which permits use, distribution and reproduction in any medium, provided the original work is properly cited and is not used for commercial purposes.

(c) 2021 The Authors. Methods in Ecology and Evolution published by John Wiley \& Sons Ltd on behalf of British Ecological Society 
pair of individuals with a hard territorial border between their home ranges; and (c) a predator with a large home range that encompassed the home ranges of multiple prey individuals. Using GPS data from white-faced capuchins Cebus capucinus, tracked on Barro Colorado Island, Panama, and sleepy lizards Tiliqua rugosa, tracked in Bundey, South Australia, we then show how the CDE can be used to estimate the locations of territorial borders, identify key resources, quantify the potential for competitive or predatory interactions and/or identify any changes in behaviour that directly result from location-specific encounter probability.

4. The CDE enables researchers to better understand the dynamics of populations of interacting individuals. Notably, the general estimation framework developed in this work builds straightforwardly off of home range estimation and requires no specialized data collection protocols. This method is now openly available via the ctmm $\mathrm{R}$ package.

\section{KEYWORDS}

animal movement, Cebus capucinus, contact, home range, interactions, Tiliqua rugosa

\section{1 | INTRODUCTION}

Linking individual behaviour with higher level processes has long been a cornerstone of ecological research (Darwin, 1859; DeAngelis \& Gross, 1992; Gil et al., 2018; Grimm \& Railsback, 2005; Hogeweg \& Hesper, 1990; Skellam, 1951; Sutherland, 1996). For motile species, this 'upscaling' is governed by how well any given movement strategy maximizes encounters with positive factors (e.g. food, mates, essential resources) and minimizes encounters with negative factors (e.g. predators and disease; Barraquand \& Murrell, 2013; Dougherty et al., 2018; Holling, 1959; Huston et al., 1988; Kareiva \& Odell, 1987; Spiegel et al., 2017; Turchin, 1998). Beyond their mechanistic role in driving population/community-level dynamics, encounters are also central to many conservation issues. For instance, an animal's probability of encountering humans and/or human-related activities is a key indicator of the potential for human-wildlife conflict (Meijaard et al., 2011; Poessel et al., 2013), while encounters with vehicles represent a serious source of mortality for many species (Bennett, 1991; Gibbs \& Shriver, 2002; Glista \& DeVault, 2008). Additionally, emerging zoonotic diseases pose significant and increasing threats to human health and the global economy (e.g. Rothan \& Byrareddy, 2020), and locations of risk are simultaneously viewed as 'hotspots' for both conservation and emerging disease (Paige et al., 2015).

Despite the keystone importance of encounter events for a broad range of ecological processes, encounter theory has not kept pace with the developments in animal tracking (Kays et al., 2015; Noonan et al., 2019; Wikelski et al., 2007) or movement modelling (Benhamou, 2014; Fleming et al., 2014a; Gurarie et al., 2009; Hooten et al., 2019; Johnson et al., 2008; Michelot \& Blackwell, 2019). Furthermore, existing work has focused primarily on the relationship between animal movement and encounter rates (e.g. Bartumeus et al., 2008; Buchin et al., 2012; Gerritsen \& Strickler, 1977; Gurarie \& Ovaskainen, 2013; Hutchinson \& Waser, 2007; Martinez-Garcia et al., 2020; Visser \& Kiørboe, 2006), while the relationship between individual movement and the spatial locations of encounter events in the environment has remained conspicuously understudied (but see, Hoover et al., 2020; Long et al., 2015; Spiegel et al., 2016). This is a notable limitation as the probability of encountering another individual has welldocumented effects on animal behaviour. The landscape of fear hypothesis, for example, is based on the concept that prey species alter their behaviour with respect to spatiotemporal predation risk (Hernández \& Laundré, 2005; Kuijper et al., 2013; Laundré et al., 2014; Lima et al., 1985). One prediction of this hypothesis is that individuals can devote more time to foraging in areas where the risk of encountering a predator is low, and should therefore balance predation risk against energetic needs while navigating their environments. Without a method for straightforwardly quantifying how the probability of encountering a predator changes in space, however, empirical work has typically relied on intensive field efforts (e.g. van der Merwe \& Brown, 2008) and/ or ad hoc proxy measures to quantify the spatial distribution of predation risk (reviewed in Gallagher et al., 2017).

Beyond the importance of encounters in driving predatorprey dynamics, the way in which intraspecific encounter probability varies in space also shapes socio-spatial arrangements. For example, while many species occupy home ranges with undefended boundaries, others maintain actively defended territories (Powell, 2000). In species with intense and potentially lethal intergroup competition, individuals tend to avoid areas near territorial boundaries, where they are likely to encounter neighbouring individuals (Mech \& Harper, 2002; Sillero-Zubiri \& Macdonald, 1998; Wrangham et al., 2007; Wrangham, Wilson \& Hauser, 2007), and are more alert when moving through these locations (Kurihara \& Hanya, 2018; Tórrez-Herrera et al., 2020; Wrangham, Wilson, et al., 2007). Indeed, Moorcroft et al. (1999) showed how individual coyotes' (Canis latrans) avoidance of areas with a high probability of encountering the scent marks of individuals from neighbouring 
packs provided a mechanistic basis for the formation of territorial boundaries (see also Moorcroft, Lewis, et al., 2006). Mechanistic home range approaches, however, require complex, mechanistic models that need to be specifically tailored to each situation (e.g. Giuggioli et al., 2013; Moorcroft, Moorcroft, et al., 2006). The difficulty in quantifying the location, permeability or even existence of territorial borders (Powell, 2000), has meant that researchers often rely on indirect measures such as patterns of home range overlap when studying animal behaviour at and around territorial boundaries (e.g. Bermejo, 2004; Tórrez-Herrera et al., 2020; Vander Wal et al., 2014).

The capacity to leverage information on animal space use to estimate the distribution of encounter locations is beneficial to a wide range of ecological research. Early work by Getty (1981) identified the relationship between location-specific 'crowding' and the local potential for encounters, but the empirical nature of Getty's work limited the generalizability of the approach. More recent studies that have attempted to relate individual movement with encounter locations have used randomization approaches to generate null models (Spiegel et al., 2016, 2018), or used the Bhattacharyya integrand, which is a by-product of home range overlap estimation, as a visual diagnostic tool (French et al., 2019). Here, we build on these studies and develop a formal statistical framework for estimating the spatial distribution of encounter events from animal tracking data. To this end, most analytical work on encounters model animal movement as either bounded ballistic (Gerritsen \& Strickler, 1977; Hutchinson \& Waser, 2007) or Brownian (Dieker, 2011; Visser, 2008; Visser \& Kiørboe, 2006) motion. A key limitation of these models, however, is that they result in uniformly distributed patterns of space use, meaning encounters between individuals also occur uniformly in space. In stark contrast, most real animals exhibit non-uniform space use within spatially restricted home ranges (Bowen, 1982; Burt, 1943; Fleming et al., 2014a; Kie et al., 2010; Martinez-Garcia et al., 2020; Moorcroft, Moorcroft, et al., 2006; Noonan, Tucker, et al., 2019; Powell, 2000), and encounters between individuals do not occur uniformly in space, but are instead concentrated at territorial boundaries (Bermejo, 2004; Ellwood et al., 2017; Nievergelt et al., 1998; Wilson et al., 2012), in/around heavily used habitats and/or habitat features (Weckel et al., 2006; Whittington et al., 2011) or at key resources (De Boer et al., 2010; Price-Rees et al., 2013). We therefore base our work on recent analytical work by Martinez-Garcia et al. (2020) incorporating non-uniform movement within home ranges into encounter theory.

We first demonstrate the general utility of this method for three simulation-based scenarios that occur routinely in biological systems: (a) a population of individuals that occupy relatively distinct home ranges, but with some degree of spatial overlap with neighbours at the edges of their ranges (e.g. Mertl-Millhollen, 1988; Wronski, 2005); (b) a pair of individuals with a hard territorial border between their home ranges (e.g. Henschel \& Skinner, 1991; Moorcroft, Lewis, et al., 2006) and (c) a predator with a large home range that encompassed the home ranges of multiple prey (e.g. Herfindal et al., 2005; Loveridge et al., 2009). We next highlight the real-world applicability of our method on GPS data from white-faced capuchins Cebus capucinus tracked on Barro Colorado Island, Panama, and sleepy lizards Tiliqua rugosa tracked in Bundey, South Australia. We show here how the spatial distribution of encounters can provide an estimate of the location of territorial borders, and demonstrate the possibility of gaining insights into species' ecology by comparing changes in movement patterns against the CDEs. We conclude with a discussion of the potential applications of this distribution for better understanding the dynamics of populations of interacting individuals.

\section{2 | MATERIALS AND METHODS}

\subsection{The conditional distribution of encounters}

Before describing the details of our conditional distribution of encounter (CDE) estimator, it is important to note at the outset that although we rely on assumptions in deriving our estimator, the spatial distribution of encounter locations is a target distribution that exists even if the assumptions of the present estimator may not be met by every dataset. Our framework for estimating the spatial distribution of encounter events in the environment is based on the assumption that the mean instantaneous encounter rate $\tilde{\mathcal{E}}_{i j}(t)$ at time $t$ between individuals indexed $i$ and $j$ with location vectors $r_{i}(t)$ and $r_{j}(t)$ is given by

$$
\tilde{\mathcal{E}}_{i j}(t)=\gamma_{i j} \int \mathrm{d} r_{i j}(t) \Phi\left(r_{i j}(t)\right) p\left(r_{i j}(t)\right)
$$

where $\gamma_{i j}$ is a proportionality constant that governs encounter risk, also termed the encounter parameter (Gurarie \& Ovaskainen, 2013), $r_{i j}=\left|r_{i}-r_{j}\right|$ is the distance between individuals $i$ and $j, \Phi\left(r_{i j}\right)$ is a relative measure of the probability of an encounter occurring when the two individuals are some distance apart (termed the 'encounter kernel') and $p\left(r_{i j}\right)$ is the probability density of separation distance $r_{i j}$ (Martinez-Garcia et al., 2020). Under the assumptions of stationarity (i.e. no change in the means or variances over time), local encounters (i.e. two individuals occurring at the same place at the same time) and uncorrelated movement between individuals, and conditional on an encounter event between individuals $i$ and $j$ taking place, Equation 1 can be reduced to the normalized product of the individual home range estimates $p_{i}(\mathbf{r})$ and $p_{j}(\mathbf{r})$

$$
\mathrm{CDE}_{i j}(\mathbf{r})=\frac{p_{i}(\mathbf{r}) p_{j}(\mathbf{r})}{\iint d^{2} \mathbf{r}^{\prime} p_{i}\left(\mathbf{r}^{\prime}\right) p_{j}\left(\mathbf{r}^{\prime}\right)}
$$

The assumption that movement is uncorrelated across individuals is valid even with cross-correlation-inducing encounters, so long as the individuals' movement is uncorrelated with one another outside of the encounter event, and the duration of encounters is relatively short compared to the home-range crossing time-scales. While the work by Martinez-Garcia et al. (2020), which formed the basis of our work, derived encounters for Ornstein-Uhlenbeck (OU) 
processes (Uhlenbeck \& Ornstein, 1930), the estimator described by Equation 2 is not constrained to $\mathrm{OU}$ processes, and full derivations are presented in Appendix S1. In Figure 1, we provide a visualization of the relationship between movement within home ranges, encounter events and the CDE for a pair of simulated trajectories generated from uncorrelated Ornstein-Uhlenbeck Foraging (OUF) processes (Fleming et al., 2014a, 2014b), which features autocorrelated positions and velocities, and a defined home range.

For some biological systems, it may be more informative to consider encounters between more than two individuals or between groups of interest (e.g. males and females, predators and prey, individuals from one group encountering individuals from another) as opposed to the unstructured distribution of encounters between all individuals in a population. Here we expand beyond individuals $i$ and $j$ to consider two groups I and J, all with otherwise similarly interacting individuals (i.e. no individuals interact more or less than any others), though this latter approximation can be relaxed by the modification of a proportionality constant (see Appendix S1). Making the same assumptions as before, the group-level CDE between individuals in group I and those in group $J$ is given by the normalized density
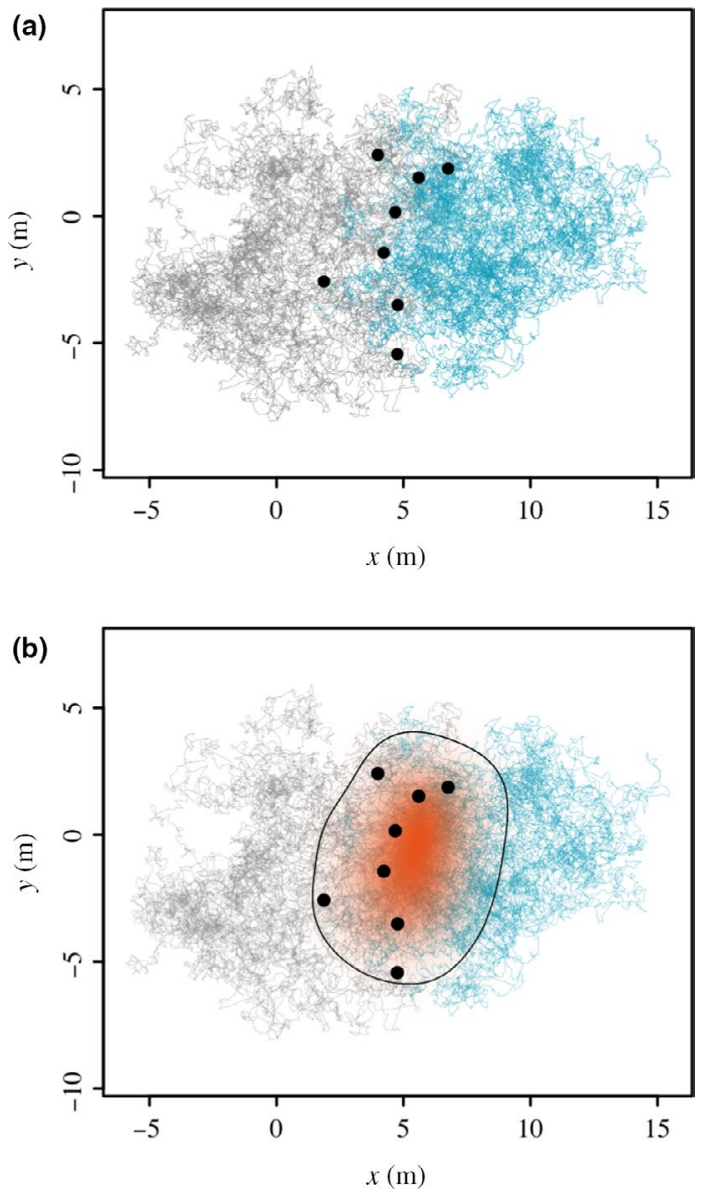

FIGURE 1 Panel (a) depicts the encounter locations (black points) for a pair of trajectories simulated from OrnsteinUhlenbeck Foraging (OUF) processes. In (b) the resulting CDE estimate (orange shading) and $95 \%$ contour are shown. For illustrative purposes, we identified encounter locations as places where the two simulated tracks were $<1 \mathrm{~m}$ apart

$$
\operatorname{CDE}_{I J}(\mathbf{r})=\frac{\sum_{i \in l j \in J} \sum_{j} p_{i}(\mathbf{r}) p_{j}(\mathbf{r})}{\iint d^{2} \mathbf{r}^{\prime} \sum_{i^{\prime} \in j^{\prime} \in J} \sum_{i^{\prime}}\left(\mathbf{r}^{\prime}\right) p_{j^{\prime}}\left(\mathbf{r}^{\prime}\right)} .
$$

The limited number of methods available for estimating the spatial distribution of encounter events has meant that, to date, researchers have often relied on describing patterns of home range overlap as an indirect proxy (e.g. Bermejo, 2004; TórrezHerrera et al., 2020; Vander Wal et al., 2014). A number of different metric are routinely used to compare trajectories, including the Bhattacharyya Coefficient (BC; Fieberg \& Kochanny, 2005; Winner et al., 2018), Kullback-Leibler divergences (Hooten et al., 2014) or earth mover's distances (Kranstauber et al., 2016). To place this approach in context with the present work, in Appendix S1, we derive an expression for the individual-level CDE in terms of home range overlap via the $\mathrm{BC}$ for $\mathrm{OU}$ movement processes. The $\mathrm{BC}$ is a measure of similarity between a pair of distributions that ranges from 0 to 1 , 1 if the two distributions are identical, and 0 if there is no shared support (Bhattacharyya, 1943). We find that the denominator of the individual-level CDE in Equation 2 is given by,

$$
\iint \mathrm{d}^{2} \mathbf{r}^{\prime} p_{i}\left(\mathbf{r}^{\prime}\right) p_{j}\left(\mathbf{r}^{\prime}\right)=\frac{\mathrm{BC}_{i j}^{2}}{8 \pi \sigma_{i j}}, \quad \sigma_{i j}=\frac{\sigma_{i} \sigma_{j}}{\sigma_{i}+\sigma_{j}},
$$

where $\sigma_{i}$ and $\sigma_{j}$ are the variances of the probability density functions for the position of each individual (both in the $x$ and $y$ coordinates because movement is assumed isotropic).

Importantly, the CDE is calculated from individual home range estimates, $p_{i}(\mathbf{r})$, which are themselves estimates derived from data. Point estimates on the CDE contours (e.g. $95 \%$ or $50 \%$ isopleths) should, therefore, be accompanied by a measure of the confidence (Pawitan, 2001). To this end, we propagate uncertainty in the home range estimates into each CDE via a combination of Gaussian reference function (GRF) approximation to the individual home range estimates, followed by the delta approximation (Cox, 2005, see Appendix S2). This estimator and, accompanying confidence intervals, is fully implemented in the encounter() function in the ctmm R package (ver. 0.5.11 and later). In Appendix S3, we provide details on a simulation study aimed at exploring the statistical performance of our CDE estimator, and the code necessary to reproduce these simulations is provided in Appendix S4.

The CDE bears qualitative resemblance with the Bhattacharyya integrand (e.g. French et al., 2019), although the later does not have a probabilistic interpretation. In Appendix S3, we also provide a sideby-side comparison of the statistical performance of the CDE and the Bhattacharyya integrand in terms of capturing the spatial distribution of encounter events.

\subsection{Workflow for estimating the CDE}

Our framework allows researchers to use animal movement data to generate a probabilistic representation of the spatial locations of 
encounter events in the environment. It does so by incorporating information on individual patterns of home range use into a spatial distribution of encounter events (i.e. the CDE). While the minimum requirement for $\mathrm{CDE}$ estimation is a pair of home range estimates, we built our framework around autocorrelated kernel density estimation (AKDE; Fleming, Fagan, et al., 2015) as modern tracking data are almost invariably autocorrelated (Noonan et al., 2020; Noonan, Tucker, et al., 2019). AKDE also benefits from having quantified uncertainty that can be propagated to the $\mathrm{CDE}$. We refer readers interested in the statistical efficiency of AKDE to Fleming and Calabrese (2017) and those interested in a comparison of AKDE to other commonly used home range estimators to recent work by Noonan, Tucker, et al. (2019).

With a prepared movement dataset in hand, the first step in the workflow is ensuring that the individuals of interest are range resident as the CDE is a long-term estimate of encounter location probabilities for movement within home ranges. When the data do not show evidence of range-residency, home range estimation, and therefore CDE estimation, is not appropriate (Calabrese et al., 2016; Fleming $\&$ Calabrese, 2017). We therefore strongly recommend starting with visual verification of range-residency via variogram analysis (Fleming et al., 2014a). Once range-residency has been verified, the next step is to fit a series of range-resident continuous-time movement models to the data, such as the Independent and Identically Distributed (IID), OU and OUF processes. Model selection should then be employed to identify the most appropriate model for the data (Fleming et al., 2014b; Fleming, Subaşı, et al., 2015; Fleming et al., 2019). With a fitted, selected movement model in hand, AKDE home range estimates can then be estimated (Fleming \& Calabrese, 2017; Fleming, Fagan, et al., 2015; Fleming et al., 2018), and these can be used to obtain CDEs.

While the CDE can be informative on its own, it is also a probability density that has contours just like a home range estimate. Placing contours on the CDE permits the identification of areas where a specified quantile (e.g. $95 \%$ or $50 \%$ ) of encounters will occur, while the error propagation techniques described above enable $\mathrm{Cl}$ s to be placed on these contours. These CDE estimates may either be the final product of the analysis, or be used in subsequent analyses such as estimating territorial boundaries, identifying changes in behaviour within the $95 \%$ CDE area or habitat features associating with high/low density regions of the CDE. The workflow we describe involves several steps. The ctmm package, however, streamlines this procedure, and a full example of the workflow is shown in Appendix S5.

\subsection{1 | Ecologically guided case studies}

To demonstrate the ecological significance of the CDE, we generated simulated datasets for three scenarios that routinely occur in biological systems: (i) a population of individuals that occupy relatively distinct home ranges, but with some degree of spatial overlap with neighbours at the edges of their ranges (e.g. Lemur catta
Mertl-Millhollen, 1988; Tragelaphus scriptus Wronski, 2005; Tiliqua rugosa Kerr \& Bull, 2006a); (ii) a pair of individuals with a hard/defended territorial border between their home ranges (e.g. Crocuta crocuta Henschel \& Skinner, 1991; C. latrans Moorcroft, Lewis, et al., 2006); and (iii) a predator with a large home range that overlaps the home ranges of multiple prey individuals (e.g. Lynx lynx Herfindal et al., 2005; Panthera leo Loveridge et al., 2009). Details for these scenarios are presented in turn.

Scenario (i): Overlapping home ranges with permeable borders. In our first scenario, we simulated tracking data for a population of seven individuals with equally sized, regularly spaced home ranges. Individuals were arranged hexagonally. For each individual, we sampled $1 \times 10^{7}$ locations from an isotropic, IID process with a spatial variance of $6,500 \mathrm{~m}^{2}$. We then estimated individual home range areas and the $95 \%$ CDE using the workflow described above.

Scenario (ii): Exclusive home ranges with hard borders. In our second scenario, we simulated tracking data for a pair of individuals with a hard territorial border between mutually exclusive home ranges. For each individual, we sampled 5,000 locations from IID processes that were Gaussian along the $y$-axis, but half normal along the $x$-axis (i.e. reflected along $x=0$ ), and with a spatial variance of $2000 \mathrm{~m}^{2}$. As above, we then estimated individual home range areas and the $95 \%$ CDE.

Scenario (iii): Predator-prey encounters. In our third scenario, we simulated tracking data for a predator with a large home range that encompassed a population of 30 prey individuals. Notably, this scenario would also be appropriate for species where large male home ranges overlap numerous smaller female ranges (Calabrese et al., 2021; Clutton-Brock, 1989). For each individual, we sampled 500 locations from an isotropic, IID process. The home range centre of the predator was set to $(0,0)$ and the spatial variance to $1 \times 10^{7} \mathrm{~m}^{2}$, while the home range centres of the prey were drawn from a bivariate Poisson distribution with spatial variances of $2000 \mathrm{~m}^{2}$. We then estimated individual home range areas as above, but here excluded all prey-prey encounters when estimating the $C D E$, so that this represented only the spatial distribution of predator-prey encounters.

We opted to simulate from IID processes for these case studies as the lack of autocorrelation allowed for more rapid convergence of the estimated home range areas and CDEs (Noonan, Tucker, et al., 2019). Here again, however, we do not expect any qualitatively different behaviour for data from autocorrelated movement processes when using a home-range estimator that accounts for said autocorrelation. We also note that the amount of data we simulated for each scenario were based on a case-specific trade-off between computation time, accuracy and visual clarity of the results.

\section{3 | Empirical studies}

\subsection{1 | White-faced capuchins}

White-faced capuchins (C. capucinus; henceforth capuchins) are New World primates that feed primarily on fruit and invertebrates 
(Chapman \& Fedigan, 1990). They are group-living, with intense (Crofoot, 2007) and potentially lethal (Gros-Louis et al., 2003) inter-group competition. Previous work on this species has found that they have home range areas of c. $8 \times 10^{5}-1.5 \times 10^{6} \mathrm{~m}^{2}$ (Tórrez-Herrera et al., 2020). Although the perceptual range of $C$. capucinus has not been assessed under field conditions, work on the closely related brown capuchin (Sapajus apella) found visual perceptual ranges of c. $8 \times 10^{3} \mathrm{~m}^{2}$ (Janson \& Di Bitetti, 1997), satisfying the assumption of perceptual ranges $\ll$ home ranges. Encounter probability plays an important role in governing capuchin behaviour, and previous work has shown that capuchins tend to avoid areas where they are likely to encounter animals from neighbouring groups (Tórrez-Herrera et al., 2020; Wrangham, Lundy, et al., 2007), and the location at which neighbouring individuals encounter one another can shape the patterns of individual participation in cooperative defence and, ultimately, conflict outcome (Crofoot \& Gilby, 2012; Crofoot et al., 2008). We applied our CDE estimation framework to tracking data from five individuals belonging to separate, neighbouring social groups on Barro Colorado Island, Panama.

Locations for these five individuals were collected every 4 min during daylight hours (6-18 hr) between December 2016 and February 2017, using GPS tracking devices (e-obs $\mathrm{GmbH}$, Gruenwald, Germany). Visual inspection of the tracking data and empirical variograms suggested these individuals occupied fixed (i.e. stationary), effectively distinct home ranges, though with narrow contact zones where home ranges overlapped at intergroup boundaries. Following the workflow described above, we estimated the CDE between these neighbouring groups. We then applied ridge estimation to the estimated CDE using the R package ks (ver. 1.11.7; Duong et al., 2007). Ridge estimation extends the problem of estimating the mode of a unimodal probability density function to higher dimensions (Chen et al., 2015). The resulting 'density ridges' are paths that follow the high-density regions of a probability distribution. In the present context, ridges represent locations where encounters are more probable and are therefore likely to be territorial edges. To understand whether the spatial distribution of encounters influenced capuchin behaviour, we subset each individual dataset into movement that occurred inside and outside of the $95 \%$ CDE, fit movement models to each of these two subsets and estimate movement speeds following Noonan, Fleming, et al. (2019). We then compared the movement speeds of animals inside and outside of the $95 \%$ CDE using the meta-regression model implemented in the $\mathrm{R}$ package METAFOR (ver. 2.1-0 Viechtbauer, 2010). This approach allowed uncertainty in each individual speed estimate to be propagated into the population-level estimate when making comparisons. To compare the CDE to the locations of encounter events, we identified the locations of 62 instances where GPS-tracked individuals were within $200 \mathrm{~m}$ of one another. As a further demonstration of the ecological relevance of the $95 \%$ CDE area, we compared the locations of 12 field-observed inter-group encounters, which were not used to estimate the $\mathrm{CDE}$, with the estimated territory boundary and $95 \%$ encounter area. To collect these observations, a team of observers conducted on-the-ground observations of the capuchin groups from 1 January 2017 through 28 February 2017. Observations lasted between 5 and 9 hr per day, where observers followed one capuchin group on foot and documented a variety of behaviours. Each of the five capuchin groups were observed at least three times during the study period; however, two of the groups were observed at a higher frequency (minimum 2 days per week for each of these two groups). Inter-group encounters between capuchin groups that occurred during the observational time period were documented on an all-occurrence basis and the GPS location of the encounter was recorded using a handheld Garmin GPS unit.

\subsection{2 | Sleepy lizards}

We further applied our workflow to GPS data from three sleepy lizards (T. rugosa) tracked in Bundey, South Australia at a field site

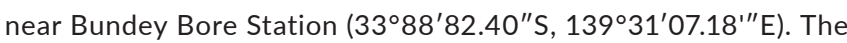
sleepy lizard is a large, long-lived, primarily herbivorous, skink from temperate regions of Australia (Kerr \& Bull, 2006b). Previous work on this species has found that they have home range areas of c. $4 \times 10^{4} \mathrm{~m}^{2}$ (Bull \& Freake, 1999), and perceptual ranges of $c$. $1.3 \times 10^{3} \mathrm{~m}^{2}$ (Auburn et al., 2009), again satisfying the assumption of perceptual ranges « home ranges. Visual inspection of the tracking data and empirical variograms suggested these individuals occupied fixed home ranges, satisfying the assumption of stationarity. In contrast to the capuchin example detailed above, sleepy lizard home ranges often overlap extensively with conspecifics (Kerr \& Bull, 2006a), but do exhibit some level of territorial defence (Spiegel et al., 2018). GPS locations for these three individuals were collected every 2 min over a $\sim 2.5$-month period in Austral spring 2017 (October-December). We estimated the CDE for these three animals following the general workflow described above. The CDE in this case was the renormalized sum of all pairwise products (excluding self-encounters) estimated using the group encounter relations. Because the outer parts of sleepy lizard home ranges overlap extensively with conspecifics, CDE areas with high probabilities may therefore relate more to the location of valuable resources than to territorial boundaries (Leu \& Bull, 2016; Sih et al., 2018). To understand how the CDE's capacity to identify key habitat features compared to more conventional approaches, we contrasted it with the area where the $95 \%$ and $50 \%$ home range contours of all three individuals intersected.

\section{3 | RESULTS}

\section{1 | Ecologically guided simulations}

In our first scenario of overlapping home ranges with permeable borders (Figure 2a), we found that this type of socio-spatial 
(a)

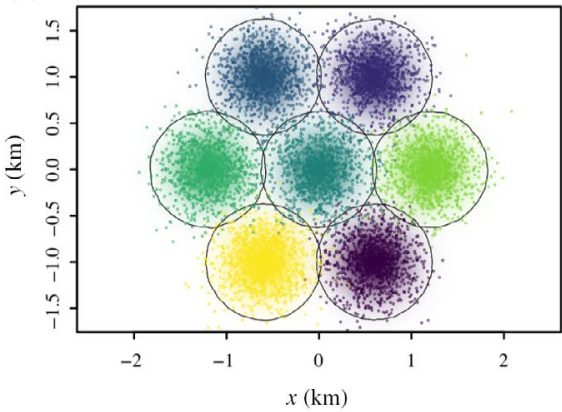

(d)

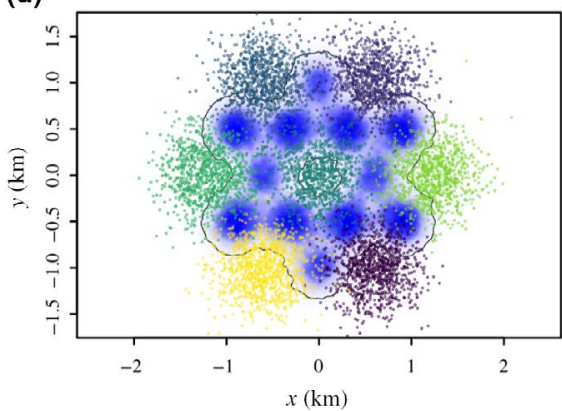

(b)

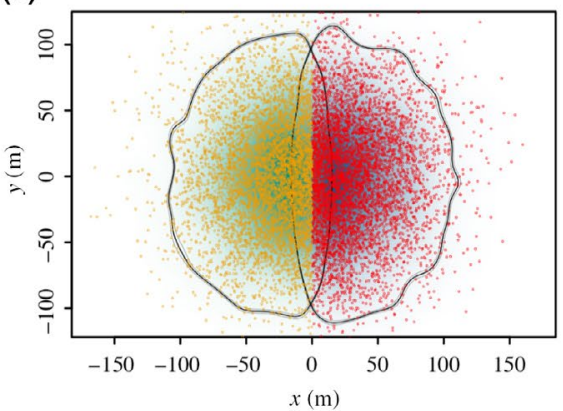

(e)

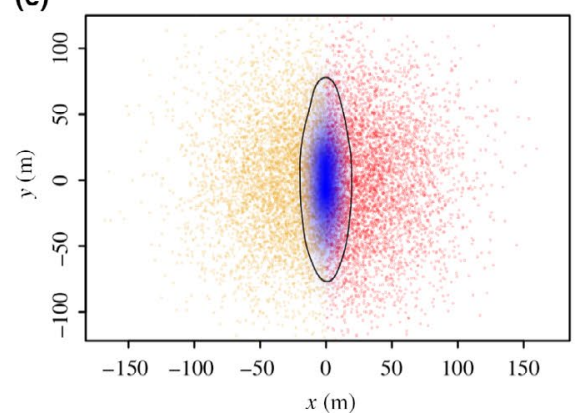

(c)

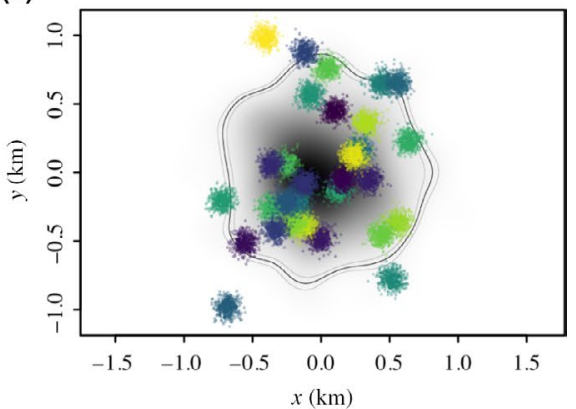

(f)

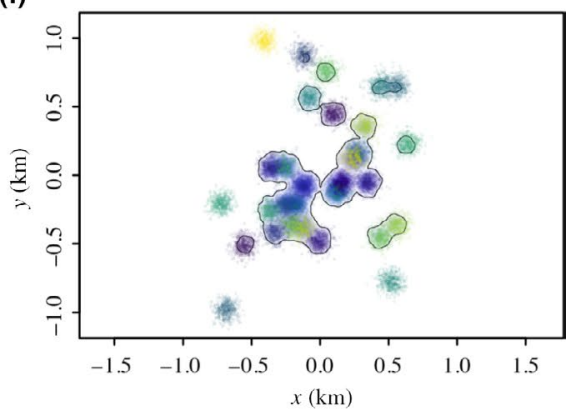

FIGURE 2 The top row depicts simulated tracking data and home range estimates for: (a) a population of individuals that occupy primarily exclusive home ranges but with overlapping boundaries; (b) a pair of individuals with a hard territorial boundary between their ranges at $x=0$; and (c) a predator (black density and contours) with a large home range that encompasses multiple smaller prey home ranges (coloured points). In the lower row, panels (d), (e) and (f), the resulting conditional distributions of encounters (CDEs) are shown in blue (darker shadings of blue represent greater probabilities)

arrangement resulted in the $95 \% \mathrm{CDE}$ area predicting encounters as being more likely to occur in boundary regions and lower probabilities towards home range centres (Figure 2d). Notably, while the bulk of the probability density was centred on the area of intersection of neighbours' 95\% home ranges, there was support for encounters occurring well beyond these areas and closer to the core of individuals' home ranges. This highlights how the area of home range intersection can underestimate the area over which encounters are likely to occur, especially when overlap is low (see also Appendix S1). In our second scenario for a pair of individuals with a hard territorial border between mutually exclusive home ranges (Figure $2 b$ ), we found that the CDE was correctly distributed along the territorial boundary, but with a spillover that was proportional to the bandwidth of the home range estimates (Figure 2e). Unsurprisingly, in our predator-prey scenario, $95 \%$ of the predator-prey encounters were predicted to occur near the centre of the predator's home range, and the home ranges of prey located near the centre of the predator's home range were entirely within the $95 \%$ CDE (Figure 2c,f). For prey near the periphery of the predator's home range, however, there were still locations within their home range that were within the $95 \% \mathrm{CDE}$, but only in heavily used areas. In other words, predation risk for these individuals was greatest not where they are closest to the predator's home range centre, but where they spent most of their time relative to where the predator went. This highlights the importance of accounting for non-uniform space use when determining the spatial distribution of predation risk.

\section{2 | Empirical case studies}

\subsection{1 | White-faced capuchins}

As would be expected for a species with intense inter-group competition, we found that spatial overlap between capuchin home ranges was low (median BC: 0.13, range: <0.01-0.28; Figure 3). Mirroring our simulation-based results above (Figure 2d), the resulting $C D E$ was centred along the boundaries between the individuals' tracking data, highlighting how most of the intergroup encounters are likely to occur at, or close to, the edges of the individuals' home ranges. Ridge estimation on the CDE resulted in estimates of the territorial boundaries that mapped onto the edges of each animal's home range (Figure 3a). In addition, we found that all 12 directly observed (i.e. by researchers in the field) encounters, and 58 of the 62 GPS observed encounters (i.e. $94.6 \%$ ) fell within the $95 \%$ contours of the CDE. These were within $193.6 \mathrm{~m}$ of the estimated territorial boundaries (median $52.6 \mathrm{~m}$; range: $1.1 \mathrm{~m}-193.6 \mathrm{~m}$ ). These findings demonstrate the direct correspondence between the 95\% CDE and capuchin ecology.

Interestingly, we also found that the capuchins we analysed modified their movement behaviour in relation to the local probability of encountering a neighbouring individual. While there was no evidence for a general relationship between movement speed and distance from home range centre $\left(R^{2}=<0.001, p=0.83\right)$, 
FIGURE 3 GPS data from five whitefaced capuchins Cebus capucinus from five neighbouring social groups tracked on Barro Colorado Island, Panama. In panel (a) the conditional distribution of encounters (CDEs) are depicted in orange shading, while the orange line delineates the $95 \%$ contour. The red lines depict the territorial borders estimated via ridge estimation on the CDEs, and the large black points represent the locations of field-observed encounters between neighbouring individuals from these five social groups, the green dots depict encounters observed from the tracking data. Note how $94.6 \%$ of the encounters occurred within the $95 \%$ contour of the CDEs. In panel (b), mean individual and population-level speed estimates for movement inside and outside of the 95\% CDE are depicted, showing how, on average, animals moved significantly more slowly when in the $95 \% \mathrm{CDE}$
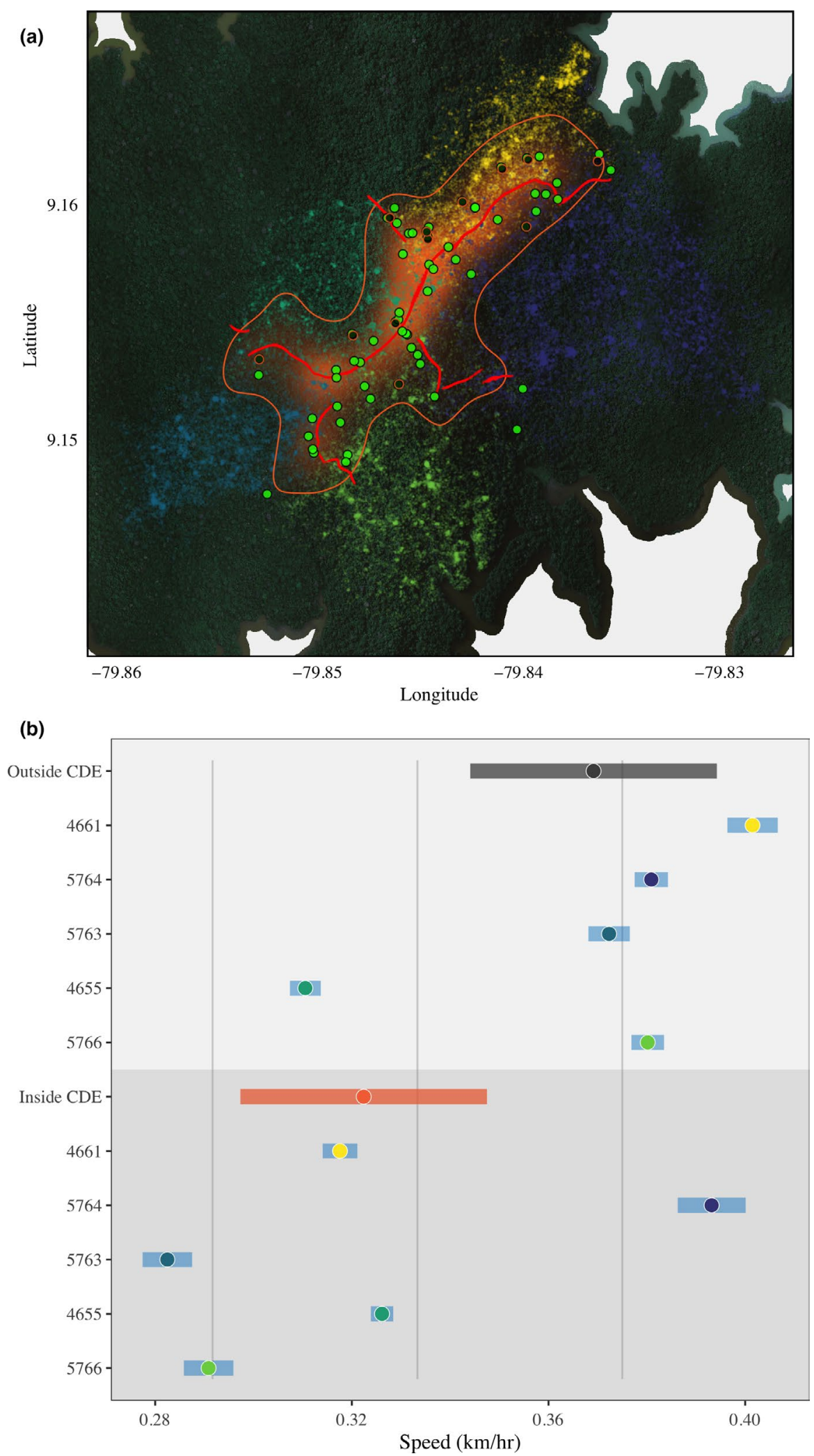

we found that when moving within their home ranges, but not within the $95 \% \mathrm{CDE}$, capuchins moved with a mean speed of $0.37 \mathrm{~km} / \mathrm{hr}$ (95\% Cls: 0.34-0.40). In contrast, animals moved significantly more slowly ( $p=0.036$ ) when moving through the $95 \%$ CDE, with a mean speed of only $0.32 \mathrm{~km} / \mathrm{hr}$ (95\% Cls: 0.30-0.35; Figure 3b).

\subsection{2 | Sleepy lizards}

Although the three sleepy lizards we analysed occupied relatively distinct home ranges with low spatial overlap (median BC: 0.23 , range: $0.13-0.39$ ), there was a focal point around the only source of standing water in the area where the home ranges of all three 

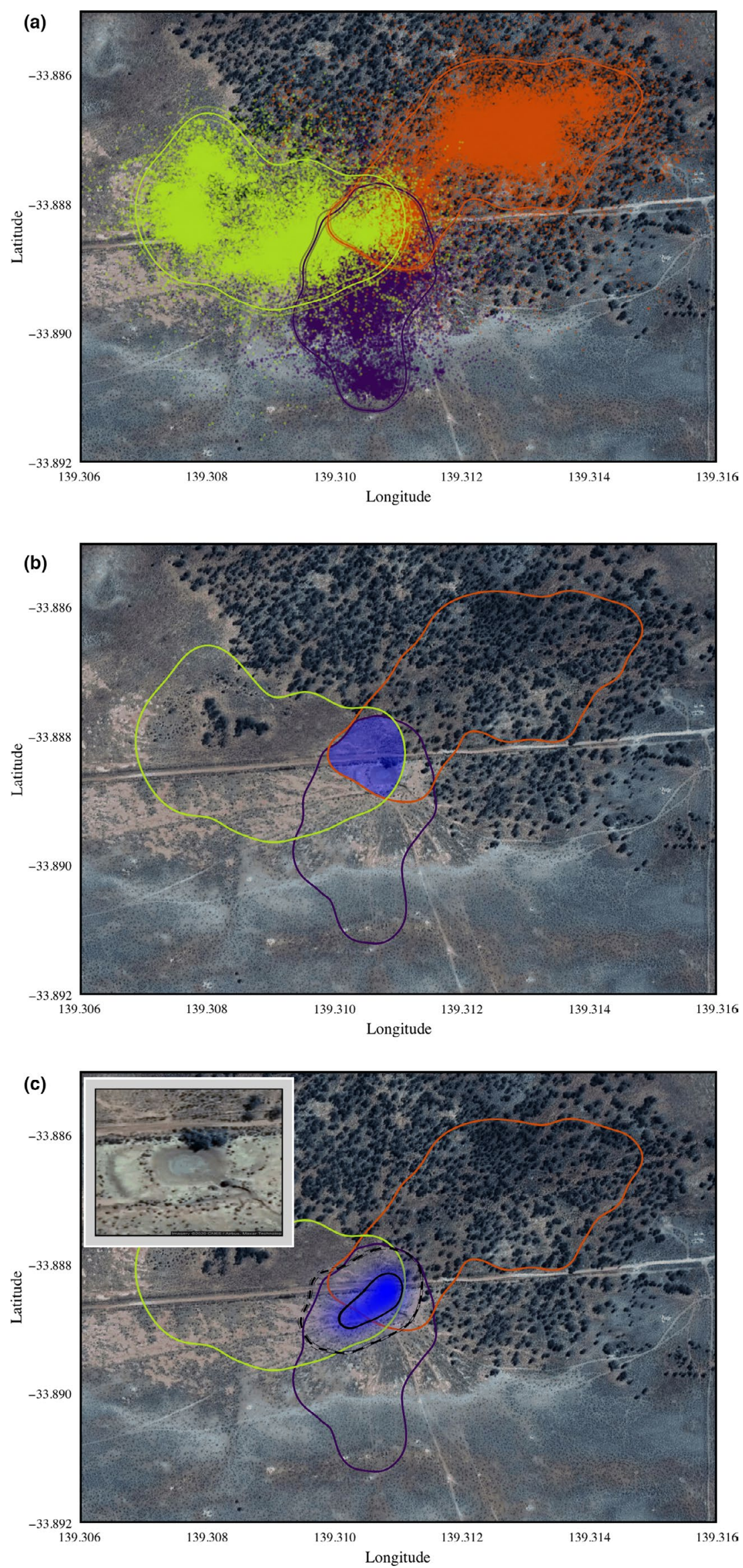

FIGURE 4 In panel (a), GPS data from three sleepy lizards (Tiliqua rugosa) tracked in Bundey, South Australia are depicted. The contours depict the estimated $95 \%$ home range areas $\pm 95 \%$ confidence intervals. Panel (b) shows the $95 \%$ home range contours, as well as the area where all three $95 \%$ home ranges intersect (blue shading). In c), the conditional distribution of encounters (CDEs) for these animals are shown in orange while the solid black line delineates the $50 \%$ contour and the dashed black line delineates the $95 \%$ contour. Note how the CDE is centred on the only watering hole in the surrounding area (inset in panel c), while the area of intersection covers space well beyond the watering hole at the $95 \%$ level 
individuals intersected (Figure 4a). For these animals, the bulk of the CDE's probability density was centred on this water source, suggesting that the majority of encounters are likely to occur at or around this valuable resource (Figure 4c). If we had applied the conventional approach of describing patterns of home range overlap, however, the area where all three home ranges intersected covered space well beyond the watering hole at the $95 \%$ level (Figure 4b), and there was no location where the $50 \%$ contours of all three animals overlap (results not shown).

\section{4 | DISCUSSION}

Intra- and inter-specific encounters are keystone ecological events that govern the dynamics of many higher level processes (Barraquand \& Murrell, 2013; Dougherty et al., 2018; Holling, 1959; Huston et al., 1988; Kareiva \& Odell, 1987; Spiegel et al., 2017; Turchin, 1998). Despite this, the relationship between individual movement strategies and encounter processes has remained conspicuously understudied. Furthermore, previous work has focused almost exclusively on relating animal movement to encounter rates (e.g. Bartumeus et al., 2008; Gerritsen \& Strickler, 1977; Gurarie \& Ovaskainen, 2013; Hutchinson \& Waser, 2007; Martinez-Garcia et al., 2020; Visser \& Kiørboe, 2006). This has left researchers interested in understanding the spatial dynamics of encounter processes with only empirically based null models (Spiegel et al., 2016, 2018) or informal measures of the spatial distribution of encounters (e.g. French et al., 2019). In response, we have derived an estimator of the spatial distribution of encounter events that builds straightforwardly off of one of the most ubiquitous analyses in movement ecologyhome-range estimation.

\subsection{Properties and assumptions of the CDE}

Before discussing the properties of the CDE estimator described in the present work, it is crucial to note that the spatial distribution of encounter locations exists even if the assumptions of our estimator are not met by the data. In other words, although the assumptions of the present estimator may not be met by every dataset, it does not negate the existence of the CDE. In deriving our CDE estimator, we relied on three key assumptions to maintain analytical tractability: (a) stationarity in the movement processes; (b) that encounters are local events; and (c) that movement is uncorrelated across individuals. Stationarity in this context refers to the fact that we are assuming the individuals of interest are range resident, and do not exhibit a range shift, or major change in home-range behaviour over time. While large-scale analyses suggest that this assumption holds true for many animal tracking datasets (Noonan et al., 2020; Noonan, Tucker, et al., 2019), we recommend verification prior to analysis, as significant changes in movement behaviour (e.g. range shifts, migrations, dispersals, etc.) will clearly influence the area over which encounters occur. In terms of encounters being local events, we anticipate this assumption holding for many species as encounters tend to occur over much shorter distances than the radii of their home range areas (e.g. Middleton et al., 2013; Muirhead \& Sprules, 2003). For species with large perceptual ranges, however, the encounter kernel in Equation 1 can be carried through in the derivations and modified to account for the greater area over which an encounter can be considered to happen. Perhaps the most important assumption of the present framework is that movement is uncorrelated across individuals. As noted above, the assumption of uncorrelated movement is still valid with cross-correlation-inducing encounters, so long as the individuals' movement is uncorrelated outside of the encounter event, and the duration of encounters is relatively short compared to the homerange crossing time-scales (e.g. encounters on the order of minutes vs. range crossing times of days). Nonetheless, correlated movement is a well-documented phenomenon that is likely to occur in a wide range of species (Calabrese et al., 2018; Couzin et al., 2005; StrandburgPeshkin et al., 2015). While expanding the current framework to account for cross-correlated movement was beyond the scope of the present study, future work on this topic is clearly warranted.

In terms of accuracy, our simulation study revealed how, because the $C D E$ is estimated conditionally on multiple home-range estimates, any biases in these will be propagated into CDE estimates. Accurate home-range estimates are therefore critical for the CDE to accurately reflect the spatial distribution of encounters between tracked individuals (see also Winner et al., 2018). For a discussion on how to obtain accurate home-range estimates, we refer readers to Noonan, Tucker, et al. (2019). In addition, more effort remains to derive bias corrections for both the Gaussian and kernel estimates. As a further limitation, it is crucial to note that the CDE requires multiple individuals, of potentially different species, to be tracked in the same place at the same time, and provides no information on encounters with unmonitored animals. In other words, if the CDE has a low location-specific probability, this does not necessarily mean an encounter is unlikely if an individual is moving through an area that is regularly visited by untracked animals. Good coverage of the local population is therefore necessary for the CDE to fully capture the spatial distribution of encounters. Importantly, while data density can be a limiting factor in practical applications, this fundamental limitation also exists for any method that quantifies encounter processes, including randomizing paths to generate null models (Spiegel et al., 2016, 2018), comparing home range overlap (e.g. Bermejo, 2004; Tórrez-Herrera et al., 2020; Vander Wal et al., 2014), or applying mechanistic home range analysis (Moorcroft et al., 1999). We therefore recommend that researchers interested in understanding encounter dynamics focus their data collection on good coverage of a localized population.

\subsection{The ecological importance of encounter distributions}

Our empirical case studies show how the CDE can be used to straightforwardly quantify key aspects of population/community dynamics. For instance, while many truly territorial species actively 
defend borders (Powell, 2000; Stamps \& Buechner, 1985) for other species, borders tend not to be rigid territorial boundaries, but permeable contact zones (Anich et al., 2009; Ellwood et al., 2017; Stewart et al., 1997). Understanding behaviour at and around territorial boundaries, however, is a deceptively challenging question that, to date, has relied on labour-intensive field efforts (e.g. Delahay et al., 2000; Kilshaw et al., 2009; Kruuk, 1972) or modelling speciesspecific mechanistic processes (Giuggioli et al., 2013; Moorcroft et al., 1999). In the capuchin data we analysed, we showed how the $95 \%$ CDE provided an accurate predictor of 12 inter-group encounters that were field-observed independent of the tracking data, as well as how application of ridge estimation on the CDE yielded an objective estimate of the territorial boundaries. Additionally, the CDE can be used to identify any changes in movement behaviour that directly result from location-specific encounter probability. For instance, despite a lack of evidence for a general relationship between movement speed and distance from home range centre, we found that when the capuchins we analysed moved through the area contained within the $95 \% \mathrm{CDE}$, they did so at a significantly slower speed than when moving through areas where encounters with neighbours were low. While the mechanisms behind this difference in movement for these individuals were not explored in the present study, this agrees with previous work which found that capuchins exploit resources in inter-group boundary areas more thoroughly and spend longer feeding in each patch they encounter (TórrezHerrera et al., 2020).

Application of our CDE framework can also be used to identify key resources and quantify location-specific potential for competition. In species with high spatial overlap, areas where encounters are more likely to occur probably relate more to valuable resources than territorial boundary dynamics. For example, in our analysis of the sleepy lizard data, instead of reflecting patterns of territoriality, the CDE was localized around the only source of standing water in the three animals' home ranges. This finding agrees with previous work in this study system that found that this water source was a valuable resource that influences the population's spatial ecology (Leu \& Bull, 2016). Notably, in this respect, neither the area of intersection of the $95 \%$ nor the $50 \%$ home ranges for these animals adequately identified this aspect of these sleepy lizard's space use. This highlights how the CDE directly captures ecologically relevant information. In contrast, describing patterns of home range overlap can require researchers to make some level of subjective judgement in their analyses, due in large part to the fact that this approach fails to account for non-uniform patterns in space use and encounter probability. Beyond the utility of the CDE in our empirical case studies, this framework can be used to investigate a wide range of intra- and interspecific relationships such as predator-prey and/or community dynamics, understanding how encounter rates vary in corridors, along key migration routes, in larger versus smaller reserves, etc. At the intraspecific level, the relationship between individual-level heterogeneity, personality and movement is currently active area of research (Barry et al., 2020; Harris et al., 2020; Harrison et al., 2019; Hertel et al., 2020; Spiegel et al., 2017). Assuming differences in phenotypic traits (e.g. age, sex or personality) manifest as variation in movement and space use, the method developed here provides a simple tool for translating individual-level variation in sociability into hot/coldspots of encounters. We anticipate that this could augment many social network studies that focus on individual heterogeneity and neglect the spatial component of social interactions (see also Spiegel et al., 2016). Finally, future work could also extend this framework to explorations of the movement and behaviour of a single individual over time (e.g. quantifying site fidelity or revisitations) as an alternative to over overlap indices or grid cell-based methods (e.g. Vázquez Diosdado et al., 2018). Given the growing interest in individual variation in movement patterns (e.g. Spiegel et al., 2017), this is a promising direction to formally quantify such differences.

\subsection{The CDE as a conservation tool}

Although the case studies presented here were focused on demonstrating the utility of the CDE for understanding basic ecological processes, understanding where key types of encounters happen is also valuable from a conservation perspective. Humanwildlife conflict represents a major conservation concern which, over the past 20 years, has gone from a barely recognized issue to a major conservation focus (Dickman, 2010; Distefano, 2005; Ravenelle \& Nyhus, 2017). The probability of encountering humans and human-related activities is a key indicator of the potential for human-wildlife conflict. Here, the CDE can be extended to model and estimate the distribution of conflict events and help focus management actions and interventions where they will have maximum effect. Road traffic incidents, for instance, where an animal encounters and is potentially hit by a car, represent a serious source of mortality for many species (Bennett, 1991; Gibbs \& Shriver, 2002; Glista \& DeVault, 2008), and carry an economic cost of $\sim \$ 1$ billon/year in Europe (Bruinderink \& Hazebroek, 1996) and $\$ 8$ billion/year in the United states (Huijser et al., 2017). Given that researchers routinely use tracking data to study interactions between animals and vehicles (Murray \& St. Clair, 2015; Neumann et al., 2012; Zimmermann et al., 2014), application of the CDE in this context would aid in better understanding how variation in traffic volume and animal movement affects road traffic incidents risk, and would provide crucial baseline information for developing effective mitigation strategies. In practice, this would involve pairing individual home range estimates with distributions of traffic volume in Equation 2 to identify areas where animal-vehicle encounters are more likely. If traffic volume is perfectly uniform across the roads the animal crosses, then the encounter locations would be concentrated on areas where the animal's home range overlaps the road, for non-uniform traffic volume, however, encounter locations would be informed both by animal and vehicle movement. Much like our animal-animal findings (e.g. Figure 4), we anticipate that this approach would provide insights that are beyond the ability of simple intersections with the home range polygon and the road line. Additionally, emerging zoonotic and anthroponotic diseases pose significant and increasing 
threats to both human and animal health, respectively (Estrada et al., 2017; Rothan \& Byrareddy, 2020), and locations of risk are simultaneously viewed as 'hotspots' for both conservation and emerging disease (Paige et al., 2015). Given the importance of accounting for animal movement when modelling disease dynamics (Dougherty et al., 2018), the CDE represents a potentially fruitful tool for identifying disease transmission hotspots.

\section{4 | Concluding remarks}

In this study we have developed methods for estimating the conditional distribution of encounter events. Conceptually, the CDE describes how encounters change in space for movement within home ranges, and solidifies what has heretofore only abstractly been defined. Furthermore, we have derived this distribution and confidence interval, implemented its statistical estimator for empirical movement data and demonstrated the broad ecological relevance of the CDE. Notably, the general estimation framework developed in this work builds straightforwardly off of home range estimation, and, as such, requires no specialized data collection protocols. CDE estimation thus allows researchers to quantify hitherto intractable aspects of population/community dynamics without the need for intensive field efforts, complex data collection or relying on ad hoc indices. This method is now openly available via command line interface through the ctmm R package (Calabrese et al., 2016; CTMM Initiative et al., 2019) or through the web-based graphical user interface available at ctmm.shinyapps.io/ctmmweb/ (Calabrese et al., 2021; Dong et al., 2017). Future extensions of this framework focused on relaxing some of the current assumptions (i.e. stationarity, local encounters and uncorrelated movement across individuals) are clearly warranted.

\section{ACKNOWLEDGEMENTS}

This work was partially funded by the Center of Advanced Systems Understanding (CASUS) which is financed by Germany's Federal Ministry of Education and Research (BMBF) and by the Saxon Ministry for Science, Culture and Tourism (SMWK) with tax funds on the basis of the budget approved by the Saxon State Parliament. WFF, CHF, and JMC were supported by NSF IIBR 1915347, and RK was supported by NSF IIBR 1914928. Packard Foundation Fellowship (2016-65130), a grant from the National Science Foundation (NSF BCS 1440755), and the Alexander von Humboldt Foundation in the framework of the Alexander von Humboldt Professorship endowed by the Federal Ministry of Education and Research awarded to MCC. Support was also provided by the Center for the Advanced Study of Collective Behavior at the University of Konstanz, DFG Centre of Excellence 2117 (ID: 422037984).

\section{AUTHORS' CONTRIBUTIONS}

M.J.N., R.M.-G., C.H.F. and J.M.C. conceived the study; C.H.F. developed the methods and open-source code; R.M.-G. derived the underlying analytical framework and provided the Spanish translation of the abstract; M.J.N. conducted the analyses and drafted the manuscript; G.H.D., M.C.C., R.K., B.T.H., D.C., E.P., A.S., D.S. and O.S. carried out the fieldwork and collected the tracking data. All the authors contributed to study concepts and writing.

\section{PEER REVIEW}

The peer review history for this article is available at https://publons. com/publon/10.1111/2041-210X.13597.

\section{DATA AVAILABILITY STATEMENT}

The white-faced capuchin Cebus capucinus and sleepy lizard Tiliqua rugosa data are openly available through the Dryad Data Repository https://doi.org/10.5061/dryad.sf7m0cg5d (Noonan et al., 2021). The ctmm code is openly available on CRAN via https://cran.r-project. org $/$ package $=$ ctmm.

\section{ORCID}

Michael J. Noonan (iD https://orcid.org/0000-0003-4512-0535

Ricardo Martinez-Garcia (iD https://orcid.

org/0000-0003-2765-8147

Grace H. Davis (iD https://orcid.org/0000-0003-1711-6985

Roland Kays (iD https://orcid.org/0000-0002-2947-6665

Ben T. Hirsch iD https://orcid.org/0000-0003-0142-7340

Eric Payne iD https://orcid.org/0000-0002-0730-0837

Andrew Sih (D) https://orcid.org/0000-0001-6161-1663

Orr Spiegel iD https://orcid.org/0000-0001-8941-3175

William F. Fagan (iD https://orcid.org/0000-0003-2433-9052

Christen H. Fleming iD https://orcid.org/0000-0002-9356-6518

Justin M. Calabrese (iD https://orcid.org/0000-0003-0575-6408

\section{REFERENCES}

Anich, N. M., Benson, T. J., \& Bednarz, J. C. (2009). Estimating territory and home-range sizes: Do singing locations alone provide an accurate estimate of space use? The Auk, 126, 626-634. https://doi. org/10.1525/auk.2009.08219

Auburn, Z. M., Bull, C. M., \& Kerr, G. D. (2009). The visual perceptual range of a lizard, Tiliqua rugosa. Journal of Ethology, 27, 75-81. https:// doi.org/10.1007/s10164-008-0086-z

Barraquand, F., \& Murrell, D. J. (2013). Scaling up predator-prey dynamics using spatial moment equations. Methods in Ecology and Evolution, 4, 276-289. https://doi.org/10.1111/2041-210X.12014

Barry, T., Gurarie, E., Cheraghi, F., Kojola, I., \& Fagan, W. F. (2020). Does dispersal make the heart grow bolder? Avoidance of anthropogenic habitat elements across wolf life history. Animal Behaviour, 166, 219231. https://doi.org/10.1016/j.anbehav.2020.06.015

Bartumeus, F., Catalan, J., Viswanathan, G., Raposo, E., \& da Luz, M. (2008). The influence of turning angles on the success of nonoriented animal searches. Journal of Theoretical Biology, 252, 43-55. https://doi.org/10.1016/j.jtbi.2008.01.009

Benhamou, S. (2014). Of scales and stationarity in animal movements. Ecology Letters, 17, 261-272. https://doi.org/10.1111/ele.12225

Bennett, A. F. (1991). Roads, roadsides and wildlife conservation: A review. In D. A. Saunders \& R. J. Hobbes (Eds.), Nature conservation 2: The role of corridors (pp. 99-118). Surrey Beatty and Sons.

Bermejo, M. (2004). Home-range use and intergroup encounters in western gorillas (Gorilla g. gorilla) at Lossi Forest, North Congo. American Journal of Primatology: Official Journal of the American Society of Primatologists, 64, 223-232. https://doi.org/10.1002/ajp.20073 
Bhattacharyya, A. (1943). On a measure of divergence between two statistical populations defined by their probability distribution. Bulletin of the Calcutta Mathematical Society, 35, 99-109.

Bowen, W. D. (1982). Home range and spatial organization of coyotes in Jasper National Park, Alberta. The Journal of Wildlife Management, 46(1), 201-216. https://doi.org/10.2307/3808423

Bruinderink, G. G., \& Hazebroek, E. (1996). Ungulate traffic collisions in Europe. Conservation Biology, 10, 1059-1067. https://doi. org/10.1046/j.1523-1739.1996.10041059.x

Buchin, K., Sijben, S., Arseneau, T. J. M., \& Willems, E. P. (2012). Detecting movement patterns using Brownian bridges. In Proceedings of the 20th International Conference on Advances in Geographic Information Systems (pp. 119-128). Association for Computing Machinery. ISBN: 9781450316910; https://doi.org/10.1145/2424321.2424338

Bull, C. M., \& Freake, M. J. (1999). Home-range fidelity in the Australian sleepy lizard, Tiliqua rugosa. Australian Journal of Zoology, 47, 125132. https://doi.org/10.1071/ZO99021

Burt, W. H. (1943). Territoriality and home range concepts as applied to mammals. Journal of Mammalogy, 24, 346-352. https://doi. org/10.2307/1374834

Calabrese, J. M., Fleming, C. H., Fagan, W. F., Rimmler, M., Kaczensky, P., Bewick, S., Leimgruber, P., \& Mueller, T. (2018). Disentangling social interactions and environmental drivers in multi-individual wildlife tracking data. Philosophical Transactions of the Royal Society B: Biological Sciences, 373, 20170007. https://doi.org/10.1098/ rstb.2017.0007

Calabrese, J. M., Fleming, C. H., \& Gurarie, E. (2016). ctmm: An R package for analyzing animal relocation data as a continuous-time stochastic process. Methods in Ecology and Evolution, 7, 1124-1132.

Calabrese, J. M., Fleming, C. H., Noonan, M. J., \& Dong, X. (2021). ctmmweb: A graphical user interface for autocorrelation-informed home range estimation. Wildlife Society Bulletin, 45(1), 162-169.

Chapman, C. A., \& Fedigan, L. M. (1990). Dietary differences between neighboring Cebus capucinus groups: Local traditions, food availability or responses to food profitability? Folia Primatologica, 54, 177186. https://doi.org/10.1159/000156442

Chen, Y. C., Genovese, C. R., \& Wasserman, L. (2015). Asymptotic theory for density ridges. The Annals of Statistics, 43, 1896-1928. https:// doi.org/10.1214/15-AOS1329

Clutton-Brock, T. H. (1989). Review lecture: Mammalian mating systems. Proceedings of the Royal Society of London B: Biological Sciences, 236, 339-372.

Couzin, I. D., Krause, J., Franks, N. R., \& Levin, S. A. (2005). Effective leadership and decision-making in animal groups on the move. Nature, 433, 513-516. https://doi.org/10.1038/nature03236

Cox, C. (2005). Delta method. Encyclopedia of biostatistics. John Wiley $\&$ Sons Ltd.

Crofoot, M. (2007). Mating and feeding competition in white-faced capuchins (Cebus capucinus): The importance of short-and long-term strategies. Behaviour, 144, 1473-1495. https://doi.org/10.1163/15685 3907782512119

Crofoot, M. C., \& Gilby, I. C. (2012). Cheating monkeys undermine group strength in enemy territory. Proceedings of the National Academy of Sciences of the United States of America, 109, 501-505. https://doi. org/10.1073/pnas.1115937109

Crofoot, M. C., Gilby, I. C., Wikelski, M. C., \& Kays, R. W. (2008). Interaction location outweighs the competitive advantage of numerical superiority in Cebus capucinus intergroup contests. Proceedings of the National Academy of Sciences of the United States of America, 105 577-581. https://doi.org/10.1073/pnas.0707749105

CTMM Initiative, Fleming, C. H., \& Calabrese, J. M. (2019). Continuoustime movement modeling.

Darwin, C. (1859). On the origin of species by means of natural selection, or the Preservation of Favoured Races in the Struggle for Life (1st ed.). John Murray. de Boer, W. F., Vis, M. J. P., de Knegt, H. J., Rowles, C., Kohi, E. M., van Langevelde, F., Peel, M., Pretorius, Y., Skidmore, A. K. Slotow, R., van Wieren, S. E., \& Prins, H. H. T. (2010). Spatial distribution of lion kills determined by the water dependency of prey species. Journal of Mammalogy, 91, 1280-1286. https://doi. org/10.1644/09-MAMM-A-392.1

DeAngelis, D. L., \& Gross, L. (Eds.). (1992). Individual-based models and approaches in ecology: Populations, communities and ecosystems. Chapman and Hall/CRC.

Delahay, R. J., Brown, J. A., Mallinson, P. J., Spyvee, P. D., Handoll, D., Rogers, L. M., \& Cheeseman, C. L. (2000). The use of marked bait in studies of the territorial organization of the European Badger (Meles meles). Mammal Review, 30, 73-87.

Dickman, A. J. (2010). Complexities of conflict: The importance of considering social factors for effectively resolving humanwildlife conflict. Animal Conservation, 13, 458-466. https://doi. org/10.1111/j.1469-1795.2010.00368.x

Dieker, A. B. (2011). Reflected Brownian motion. American Cancer Society.

Distefano, E. (2005). Human-wildlife conflict worldwide: Collection of case studies, analysis of management strategies and good practices. Food and Agricultural Organization of the United Nations (FAO), Sustainable Agriculture and Rural Development Initiative (SARDI).

Dong, X., Fleming, C. H., \& Calabrese, J. M. (2017). ctmm webapp: A graphical user interface for the ctmm $R$ package.

Dougherty, E. R., Seidel, D. P., Carlson, C. J., Spiegel, O., \& Getz, W. M. (2018). Going through the motions: Incorporating movement analyses into disease research. Ecology Letters, 21, 588-604. https://doi. org/10.1111/ele.12917

Duong, T. (2007). ks: Kernel density estimation and kernel discriminant analysis for multivariate data in r. Journal of Statistical Software, 21, 211-216.

Ellwood, S. A., Newman, C., Montgomery, R. A., Nicosia, V., Buesching, C. D., Markham, A., Mascolo, C., Trigoni, N., Pásztor, B., Dyo, V., Latora, V., Baker, S. E., \& Macdonald, D. W. (2017). An activeradio-frequency-identification system capable of identifying colocations and social-structure: Validation with a wild free-ranging animal. Methods in Ecology and Evolution, 8, 1822-1831. https://doi. org/10.1111/2041-210X.12839

Estrada, A., Garber, P. A., Rylands, A. B., Roos, C., Fernandez-Duque, E., Di Fiore, A., Nekaris, K.-I., Nijman, V., Heymann, E. W., Lambert, J. E., Rovero, F., Barelli, C., Setchell, J. M., Gillespie, T. R., Mittermeier R. A., Arregoitia, L. V., de Guinea, M., Gouveia, S., Dobrovolski, R., ... Li, B. (2017). Impending extinction crisis of the world's primates: Why primates matter. Science Advances, 3, e1600946. https://doi. org/10.1126/sciadv.1600946

Fieberg, J., \& Kochanny, C. O. (2005). Quantifying home-range overlap: The importance of the utilization distribution. Journal of Wildlife Management, 69, 1346-1359.

Fleming, C. H., \& Calabrese, J. M. (2017). A new kernel density estimator for accurate home-range and species-range area estimation. Methods in Ecology and Evolution, 8, 571-579. https://doi. org/10.1111/2041-210X.12673

Fleming, C. H., Calabrese, J. M., Mueller, T., Olson, K. A., Leimgruber, P., \& Fagan, W. F. (2014a). From fine-scale foraging to home ranges: A semivariance approach to identifying movement modes across spatiotemporal scales. The American Naturalist, 183, E154-E167. https:// doi.org/10.1086/675504

Fleming, C. H., Calabrese, J. M., Mueller, T., Olson, K. A., Leimgruber, P., \& Fagan, W. F. (2014b). Non-Markovian maximum likelihood estimation of autocorrelated movement processes. Methods in Ecology and Evolution, 5, 462-472. https://doi.org/10.1111/2041-210X.12176

Fleming, C. H., Fagan, W. F., Mueller, T., Olson, K. A., Leimgruber, P., \& Calabrese, J. M. (2015). Rigorous home range estimation with movement data: A new autocorrelated kernel density estimator. Ecology, 96, 1182-1188. https://doi.org/10.1890/14-2010.1 
Fleming, C. H., Noonan, M. J., Medici, E. P., \& Calabrese, J. M. (2019). Overcoming the challenge of small effective sample sizes in homerange estimation. Methods in Ecology and Evolution, 10, 1679-1689. https://doi.org/10.1111/2041-210X.13270

Fleming, C. H., Sheldon, D., Fagan, W. F., Leimgruber, P., Mueller, T., Nandintsetseg, D., Noonan, M. J., Olson, K. A., Setyawan, E., Sianipar, A., \& Calabrese, J. M. (2018). Correcting for missing and irregular data in home-range estimation. Ecological Applications, 28, 10031010. https://doi.org/10.1002/eap.1704

Fleming, C. H., Subaşı, Y., \& Calabrese, J. M. (2015). Maximum-entropy description of animal movement. Physical Review E, Statistical, Nonlinear, and Soft Matter Physics, 91, 032107. https://doi.org/10.1103/PhysR evE.91.032107

French, J. T., Wang, H. H., Grant, W. E., \& Tomeček, J. M. (2019). Dynamics of animal joint space use: A novel application of a time series approach. Movement Ecology, 7, 1-12. https://doi.org/10.1186/ s40462-019-0183-3

Gallagher, A. J., Creel, S., Wilson, R. P., \& Cooke, S. J. (2017). Energy landscapes and the landscape of fear. Trends in Ecology \& Evolution, 32, 88-96. https://doi.org/10.1016/j.tree.2016.10.010

Gerritsen, J., \& Strickler, J. R. (1977). Encounter probabilities and community structure in zooplankton: A mathematical model. Journal of the Fisheries Board of Canada, 34, 73-82. https://doi.org/10.1139/f77-008

Getty, T. (1981). Territorial behavior of eastern chipmunks (Tamias striatus): Encounter avoidance and spatial time-sharing. Ecology, 62, 915921. https://doi.org/10.2307/1936989

Gibbs, J. P., \& Shriver, W. G. (2002). Estimating the effects of road mortality on turtle populations. Conservation Biology, 16, 1647-1652. https://doi.org/10.1046/j.1523-1739.2002.01215.x

Gil, M. A., Hein, A. M., Spiegel, O., Baskett, M. L., \& Sih, A. (2018). Social information links individual behavior to population and community dynamics. Trends in Ecology \& Evolution, 33, 535-548. https://doi. org/10.1016/j.tree.2018.04.010

Giuggioli, L., Potts, J. R., Rubenstein, D. I., \& Levin, S. A. (2013). Stigmergy, collective actions, and animal social spacing. Proceedings of the National Academy of Sciences of the United States of America, 110, 16904-16909. https://doi.org/10.1073/pnas.1307071110

Glista, D. J., \& DeVault, T. L. (2008). Vertebrate road mortality predominantly impacts amphibians. Herpetological Conservation and Biology, 3, 77-87.

Grimm, V., \& Railsback, S. F. (2005). Individual-based modeling and ecology (Vol. 8). Princeton University Press.

Gros-Louis, J., Perry, S., \& Manson, J. H. (2003). Violent coalitionary attacks and intraspecific killing in wild white-faced capuchin monkeys (Cebus capucinus). Primates, 44, 341-346. https://doi.org/10.1007/ s10329-003-0050-z

Gurarie, E., Andrews, R. D., \& Laidre, K. L. (2009). A novel method for identifying behavioural changes in animal movement data. Ecology Letters, 12, 395-408. https://doi.org/10.1111/j.1461-0248.2009.01293.x

Gurarie, E., \& Ovaskainen, O. (2013). Towards a general formalization of encounter rates in ecology. Theoretical Ecology, 6, 189-202. https:// doi.org/10.1007/s12080-012-0170-4

Harris, S. M., Descamps, S., Sneddon, L. U., Bertrand, P., Chastel, O., \& Patrick, S. C. (2020). Personality predicts foraging site fidelity and trip repeatability in a marine predator. Journal of Animal Ecology, 89, 68-79. https://doi.org/10.1111/1365-2656.13106

Harrison, P. M., Keeler, R. A., Robichaud, D., Mossop, B., Power, M., \& Cooke, S. J. (2019). Individual differences exceed species differences in the movements of a river fish community. Behavioral Ecology, 30, 1289-1297. https://doi.org/10.1093/beheco/arz076

Henschel, J. R., \& Skinner, J. D. (1991). Territorial behaviour by a clan of spotted hyaenas Crocuta crocuta. Ethology, 88, 223-235. https://doi. org/10.1111/j.1439-0310.1991.tb00277.x

Herfindal, I., Linnell, J. D., Odden, J., Nilsen, E. B., \& Andersen, R. (2005). Prey density, environmental productivity and home-range size in the
Eurasian lynx (Lynx lynx). Journal of Zoology, 265, 63-71. https://doi. org/10.1017/S0952836904006053

Hernández, L., \& Laundré, J. W. (2005). Foraging in the 'landscape of fear' and its implications for habitat use and diet quality of elk Cervus elaphus and bison Bison bison. Wildlife Biology, 11, 215-220.

Hertel, A. G., Niemelä, P. T., Dingemanse, N. J., \& Mueller, T. (2020). A guide for studying among-individual behavioral variation from movement data in the wild. Movement Ecology, 8, 1-18. https://doi. org/10.1186/s40462-020-00216-8

Hogeweg, P., \& Hesper, B. (1990). Individual-oriented modelling in ecology. Mathematical and Computer Modelling, 13, 83-90. https://doi. org/10.1016/0895-7177(90)90012-C

Holling, C. S. (1959). The components of predation as revealed by a study of small-mammal predation of the European pine sawfly. The Canadian Entomologist, 91, 293-320. https://doi.org/10.4039/Ent91 293-5

Hooten, M., Hanks, E., Johnson, D., \& Alldredge, M. (2014). Temporal variation and scale in movement-based resource selection functions. Statistical Methodology, 17, 82-98. https://doi.org/10.1016/j. stamet.2012.12.001

Hooten, M. B., Scharf, H. R., \& Morales, J. M. (2019). Running on empty: Recharge dynamics from animal movement data. Ecology Letters, 22, 377-389.

Hoover, B. A., Miller, J. A., \& Long, J. (2020). Mapping areas of asynchronous-temporal interaction in animal-telemetry data. Transactions in GIS, 24(3), 573-586. https://doi.org/10.1111/ tgis.12622

Huijser, M. P., McGowan, P., Hardy, A., Kociolek, A., Clevenger, A., Smith, D., \& Ament, R. (2017). Wildlife-vehicle collision reduction study: Report to congress. Technical report, Federal Highway Administration.

Huston, M., DeAngelis, D., \& Post, W. (1988). New computer models unify ecological theory: Computer simulations show that many ecological patterns can be explained by interactions among individual organisms. BioScience, 38, 682-691. https://doi.org/10.2307/1310870

Hutchinson, J. M., \& Waser, P. M. (2007). Use, misuse and extensions of 'ideal gas' models of animal encounter. Biological Reviews, 82, 335359. https://doi.org/10.1111/j.1469-185X.2007.00014.x

Janson, C. H., \& Di Bitetti, M. S. (1997). Experimental analysis of food detection in capuchin monkeys: Effects of distance, travel speed, and resource size. Behavioral Ecology and Sociobiology, 41, 17-24. https:// doi.org/10.1007/s002650050359

Johnson, D. S., London, J. M., Lea, M. A., \& Durban, J. W. (2008). Continuous-time correlated random walk model for animal telemetry data. Ecology, 89, 1208-1215. https://doi.org/10.1890/07-1032.1

Kareiva, P., \& Odell, G. (1987). Swarms of predators exhibit 'preytaxis' if individual predators use area-restricted search. The American Naturalist, 130, 233-270. https://doi.org/10.1086/284707

Kays, R., Crofoot, M. C., Jetz, W., \& Wikelski, M. (2015). Terrestrial animal tracking as an eye on life and planet. Science, 348, aaa2478. https:// doi.org/10.1126/science.aaa2478

Kerr, G. D., \& Bull, C. M. (2006a). Exclusive core areas in overlapping ranges of the sleepy lizard, Tiliqua rugosa. Behavioral Ecology, 17, 380391. https://doi.org/10.1093/beheco/arj041

Kerr, G. D., \& Bull, C. M. (2006b). Movement patterns in the monogamous sleepy lizard (Tiliqua rugosa): Effects of gender, drought, time of year and time of day. Journal of Zoology, 269, 137-147. https://doi. org/10.1111/j.1469-7998.2006.00091.x

Kie, J. G., Matthiopoulos, J., Fieberg, J., Powell, R. A., Cagnacci, F., Mitchell, M. S., Gaillard, J. M., \& Moorcroft, P. R. (2010). The homerange concept: Are traditional estimators still relevant with modern telemetry technology? Philosophical Transactions of the Royal Society of London Series B: Biological Sciences, 365, 2221-2231. https://doi. org/10.1098/rstb.2010.0093

Kilshaw, K., Newman, C., Buesching, C., Bunyan, J., \& Macdonald, D. W. (2009). Coordinated latrine use by European Badgers, Meles meles: 
Potential consequences for territory defense. American Society of Mammalogists, 90, 1188-1198.

Kranstauber, B., Smolla, M., \& Safi, K. (2016). Similarity in spatial utilization distributions measured by the earth mover's distance. Methods in Ecology and Evolution, 8, 155-160. https://doi. org/10.1111/2041-210X.12649

Kruuk, H. (1972). The spotted hyena: A study of predation and social behavior. University of Chicago Press.

Kuijper, D. P. J., de Kleine, C., Churski, M., van Hooft, P., Bubnicki, J., \& Jędrzejewska, B. (2013). Landscape of fear in Europe: Wolves affect spatial patterns of ungulate browsing in białowieża primeval forest, Poland. Ecography, 36, 1263-1275. https://doi. org/10.1111/j.1600-0587.2013.00266.x

Kurihara, Y., \& Hanya, G. (2018). Within-population variations in home range use and food patch use of Japanese macaques: A perspective of intergroup hostility. Folia Primatologica, 89, 397-414. https://doi. org/10.1159/000493574

Laundré, J. W., Hernández, L., Medina, P. L., Campanella, A., LópezPortillo, J., González-Romero, A., Grajales-Tam, K. M., Burke, A. M., Gronemeyer, P., \& Browning, D. M. (2014). The landscape of fear: The missing link to understand top-down and bottom-up controls of prey abundance? Ecology, 95, 1141-1152. https://doi. org/10.1890/13-1083.1

Leu, S. T., \& Bull, C. M. (2016). Artificial water point for livestock influences spatial ecology of a native lizard species. PLoS ONE, 11, e0147433. https://doi.org/10.1371/journal.pone.0147433

Lima, S. L., Valone, T. J., \& Caraco, T. (1985). Foraging-efficiencypredation-risk trade-off in the grey squirrel. Animal Behaviour, 33, 155-165. https://doi.org/10.1016/S0003-3472(85)80129-9

Long, J. A., Webb, S. L., Nelson, T. A., \& Gee, K. L. (2015). Mapping areas of spatial-temporal overlap from wildlife tracking data. Movement Ecology, 3, 38. https://doi.org/10.1186/s40462-015-0064-3

Loveridge, A. J., Valeix, M., Davidson, Z., Murindagomo, F., Fritz, H., \& Macdonald, D. W. (2009). Changes in home range size of african lions in relation to pride size and prey biomass in a semiarid savanna. Ecography, 32, 953-962. https://doi.org/10.1111/ j.1600-0587.2009.05745.x

Martinez-Garcia, R., Fleming, C. H., Seppelt, R., Fagan, W. F., \& Calabrese, J. M. (2020). How range residency and long-range perception change encounter rates. Journal of Theoretical Biology, 498, 110267. https:// doi.org/10.1016/j.jtbi.2020.110267

Mech, L. D., \& Harper, E. K. (2002). Differential use of a wolf, Canis lupus, pack territory edge and core. Canadian Field-Naturalist, 116, 315-316.

Meijaard, E., Buchori, D., Hadiprakarsa, Y., Utami-Atmoko, S. S., Nurcahyo, A., Tjiu, A., Prasetyo, D., Nardiyono, Christie, L., Ancrenaz, M., Abadi, F., Antoni, I. N. G., Armayadi, D., Dinato, A., Ella, Gumelar, P., Indrawan, T. P., Kussaritano, Munajat, C., ... Mengersen, K. (2011). Quantifying killing of orangutans and human-orangutan conflict in Kalimantan, Indonesia. PLoS ONE, 6, e27491. https://doi. org/10.1371/journal.pone.0027491

Mertl-Millhollen, A. S. (1988). Olfactory demarcation of territorial but not home range boundaries by Lemur catta. Folia Primatologica, 50, 175-187.

Michelot, T., \& Blackwell, P. G. (2019). State-switching continuous-time correlated random walks. Methods in Ecology and Evolution, 10, 637649. https://doi.org/10.1111/2041-210X.13154

Middleton, A. D., Kauffman, M. J., McWhirter, D. E., Jimenez, M. D., Cook, R. C., Cook, J. G., Albeke, S. E., Sawyer, H., \& White, P. (2013). Linking anti-predator behaviour to prey demography reveals limited risk effects of an actively hunting large carnivore. Ecology Letters, 16, 1023-1030. https://doi.org/10.1111/ele.12133

Moorcroft, P. R., Lewis, M. A., \& Crabtree, R. L. (1999). Home range analysis using a mechanistic home range model. Ecology, 80, 1656-1665.

Moorcroft, P. R., Lewis, M. A., \& Crabtree, R. L. (2006). Mechanistic home range models capture spatial patterns and dynamics of coyote territories in yellowstone. Proceedings of the Royal Society B: Biological Sciences, 273, 1651-1659. https://doi.org/10.1098/rspb.2005.3439

Moorcroft, P. R., Moorcroft, P., \& Lewis, M. A. (2006). Mechanistic home range analysis. Princeton University Press.

Muirhead, J., \& Sprules, W. G. (2003). Reaction distance of Bythotrephes longimanus, encounter rate and index of prey risk for Harp Lake, Ontario. Freshwater Biology, 48, 135-146.

Murray, M. H., \& St. Clair, C. C. (2015). Individual flexibility in nocturnal activity reduces risk of road mortality for an urban carnivore. Behavioral Ecology, 26, 1520-1527. https://doi.org/10.1093/beheco/ arv102

Neumann, W., Ericsson, G., Dettki, H., Bunnefeld, N., Keuler, N. S., Helmers, D. P., \& Radeloff, V. C. (2012). Difference in spatiotemporal patterns of wildlife road-crossings and wildlife-vehicle collisions. Biological Conservation, 145, 70-78. https://doi.org/10.1016/ j.biocon.2011.10.011

Nievergelt, C. M., Mutschler, T., \& Feistner, A. T. (1998). Group encounters and territoriality in wild Alaotran gentle lemurs (Hapalemur griseus alaotrensis). American Journal of Primatology, 46, 251-258.

Noonan, M. J., Fleming, C. H., Akre, T., Dresher-Lehman, J., Harrison, A., Gurarie, E., Kays, R., \& Calabrese, J. M. (2019). Scale-insensitive estimation of speed and distance traveled from animal tracking data. Movement Ecology, 7, 1-15. https://doi.org/10.1186/s4046 2-019-0177-1

Noonan, M. J., Fleming, C. H., Tucker, M. A., Kays, R., Harrison, A.-L., Crofoot, M. C., Abrahms, B., Alberts, S. C., Ali, A. H., Altmann, J., Antunes, P. C., Attias, N., Belant, J. L., Beyer, D. E., Bidner, L. R., Blaum, N., Boone, R. B., Caillaud, D., Paula, R. C., ... Calabrese, J. M. (2020). Effects of body size on estimation of mammalian area requirements. Conservation Biology, 34, 1017-1028. https://doi. org/10.1111/cobi.13495

Noonan, M. J., Markham, A., Newman, C., Trigoni, N., Buesching, C. D., Ellwood, S. A., \& Macdonald, D. W. (2015). A new Magneto-Inductive tracking technique to uncover subterranean activity: What do animals do underground? Methods in Ecology and Evolution, 6, 510-520. https://doi.org/10.1111/2041-210X.12348

Noonan, M. J., Martinez-Garcia, R., Davis, G. H., Crofoot, M. C., Kays, R., Hirsch, B. T., Caillaud, D., Payne, E., Sih, A., Sinn, D. L., Spiegel, O., Fagan, W. F., Fleming, C. H., \& Calabrese, J. M. (2021). Data from: Estimating encounter location distributions from animal tracking data. Dryad Data Repository, https://doi.org/10.5061/dryad.sf7m0cg5d

Noonan, M. J., Tucker, M. A., Fleming, C. H., Akre, T. S., Alberts, S. C., Ali, A. H., Altmann, J., Antunes, P. C., Belant, J. L., Beyer, D., Blaum, N., Böhning-Gaese, K., Cullen, L., Paula, R. C., Dekker, J., DrescherLehman, J., Farwig, N., Fichtel, C., Fischer, C., ... Calabrese, J. M. (2019). A comprehensive analysis of autocorrelation and bias in home range estimation. Ecological Monographs, 89, e01344. https:// doi.org/10.1002/ecm.1344

Paige, S. B., Malavé, C., Mbabazi, E., Mayer, J., \& Goldberg, T. L. (2015). Uncovering zoonoses awareness in an emerging disease 'hotspot'. Social Science \& Medicine, 129, 78-86. https://doi.org/10.1016/j. socscimed.2014.07.058

Pawitan, Y. (2001). In all likelihood: Statistical modelling and inference using likelihood. Clarendon Press.

Poessel, S. A., Breck, S. W., Teel, T. L., Shwiff, S., Crooks, K. R., \& Angeloni, L. (2013). Patterns of human-coyote conflicts in the Denver metropolitan area. The Journal of Wildlife Management, 77, 297-305. https://doi.org/10.1002/jwmg.454

Powell, R. A. (2000). Animal home ranges and territories and home range estimators. In L. Boitani \& T. F. Fuller (Eds.), Research techniques in animal ecology (pp. 65-110). Columbia University Press.

Price-Rees, S. J., Brown, G. P., \& Shine, R. (2013). Habitat selection by bluetongue lizards (Tiliqua, Scincidae) in tropical Australia: A study using GPS telemetry. Animal Biotelemetry, 1, 7. https://doi. org/10.1186/2050-3385-1-7 
Ravenelle, J., \& Nyhus, P. J. (2017). Global patterns and trends in humanwildlife conflict compensation. Conservation Biology, 31, 1247-1256. https://doi.org/10.1111/cobi.12948

Rothan, H. A., \& Byrareddy, S. N. (2020). The epidemiology and pathogenesis of coronavirus disease (Covid-19) outbreak. Journal of Autoimmunity, 109, 102433. https://doi.org/10.1016/j.jaut.2020. 102433

Sih, A., Spiegel, O., Godfrey, S., Leu, S., \& Bull, C. M. (2018). Integrating social networks, animal personalities, movement ecology and parasites: A framework with examples from a lizard. Animal Behaviour, 136, 195-205. https://doi.org/10.1016/j.anbehav.2017.09.008

Sillero-Zubiri, C., \& Macdonald, D. W. (1998). Scent-marking and territorial behaviour of Ethiopian wolves Canis simensis. Journal of Zoology, 245, 351-361. https://doi.org/10.1111/j.1469-7998.1998.tb00110.x

Skellam, J. G. (1951). Random dispersal in theoretical populations. Biometrika, 38, 196-218. https://doi.org/10.1093/biomet/38.1-2.196

Spiegel, O., Leu, S. T., Bull, C. M., \& Sih, A. (2017). What's your move? Movement as a link between personality and spatial dynamics in animal populations. Ecology Letters, 20, 3-18. https://doi.org/10.1111/ ele.12708

Spiegel, O., Leu, S. T., Sih, A., \& Bull, C. M. (2016). Socially interacting or indifferent neighbours? Randomization of movement paths to tease apart social preference and spatial constraints. Methods in Ecology and Evolution, 7, 971-979. https://doi.org/10.1111/2041210X.12553

Spiegel, O., Sih, A., Leu, S. T., \& Bull, C. M. (2018). Where should we meet? Mapping social network interactions of sleepy lizards shows sex-dependent social network structure. Animal Behaviour, 136, 207215. https://doi.org/10.1016/j.anbehav.2017.11.001

Stamps, J. A., \& Buechner, M. (1985). The territorial defense hypothesis and the ecology of insular vertebrates. The Quarterly Review of Biology, 60, 155-181. https://doi.org/10.1086/414314

Stewart, P. D., Anderson, C., \& Macdonald, D. W. (1997). A Mechanism for Passive Range Exclusion: Evidence from the European Badger (Meles meles). Journal of Theoretical Biology, 184, 279-289. https:// doi.org/10.1006/jtbi.1996.0248

Strandburg-Peshkin, A., Farine, D. R., Couzin, I. D., \& Crofoot, M. C. (2015). Shared decision-making drives collective movement in wild baboons. Science, 348, 1358-1361. https://doi.org/10.1126/science. aaa5099

Sutherland, W. J. (1996). From individual behaviour to population ecology (Vol. 11). Oxford University Press on Demand.

Tórrez-Herrera, L. L., Davis, G. H., \& Crofoot, M. C. (2020). Do monkeys avoid areas of home range overlap because they are dangerous? A test of the Risk Hypothesis in white-faced capuchin monkeys (Cebus capucinus). International Journal of Primatology, 41, 246-264. https:// doi.org/10.1007/s10764-019-00110-0

Turchin, P. (1998). Quantitative analysis of movement. Sinauer.

Uhlenbeck, G. E., \& Ornstein, L. S. (1930). On the theory of the Brownian motion. Physical Review, 36, 823-841. https://doi.org/10.1103/ PhysRev.36.823

van der Merwe, M., \& Brown, J. S. (2008). Mapping the landscape of fear of the cape ground squirrel (Xerus inauris). Journal of Mammalogy, 89, 1162-1169. https://doi.org/10.1644/08-MAMM-A-035.1

Vander Wal, E., Laforge, M. P., \& McLoughlin, P. D. (2014). Density dependence in social behaviour: Home range overlap and density interacts to affect conspecific encounter rates in a gregarious ungulate. Behavioral Ecology and Sociobiology, 68, 383-390. https://doi. org/10.1007/s00265-013-1652-0

Vázquez Diosdado, J. A., Barker, Z. E., Hodges, H. R., Amory, J. R., Croft, D. P., Bell, N. J., \& Codling, E. A. (2018). Space-use patterns highlight behavioural differences linked to lameness, parity, and days in milk in barn-housed dairy cows. PLoS ONE, 13, e0208424. https://doi. org/10.1371/journal.pone.0208424

Viechtbauer, W. (2010). Conducting meta-analyses in R with the metafor package. Journal of Statistical Software, 36, 1-48.

Visser, A. W. (2008). Lagrangian modelling of plankton motion: From deceptively simple random walks to Fokker-Planck and back again. Journal of Marine Systems, 70, 287-299. https://doi.org/10.1016/ j.jmarsys.2006.07.007

Visser, A. W., \& Kiørboe, T. (2006). Plankton motility patterns and encounter rates. Oecologia, 148, 538-546. https://doi.org/10.1007/ s00442-006-0385-4

Weckel, M., Giuliano, W., \& Silver, S. (2006). Jaguar (Panthera onca) feeding ecology: Distribution of predator and prey through time and space. Journal of Zoology, 270, 25-30. https://doi.org/ 10.1111/j.1469-7998.2006.00106.x

Whittington, J., Hebblewhite, M., DeCesare, N. J., Neufeld, L., Bradley, M., Wilmshurst, J., \& Musiani, M. (2011). Caribou encounters with wolves increase near roads and trails: A time-to-event approach. Journal of Applied Ecology, 48, 1535-1542. https://doi.org/ 10.1111/j.1365-2664.2011.02043.x

Wikelski, M., Kays, R. W., Kasdin, N. J., Thorup, K., Smith, J. A., \& Swenson, G. W. (2007). Going wild: What a global small-animal tracking system could do for experimental biologists. Journal of Experimental Biology, 210, 181-186. https://doi.org/10.1242/jeb.02629

Wilson, M. L., Kahlenberg, S. M., Wells, M., \& Wrangham, R. W. (2012). Ecological and social factors affect the occurrence and outcomes of intergroup encounters in chimpanzees. Animal Behaviour, 83, 277291. https://doi.org/10.1016/j.anbehav.2011.11.004

Winner, K., Noonan, M. J., Fleming, C. H., Olson, K. A., Mueller, T., Sheldon, D., \& Calabrese, J. M. (2018). Statistical inference for home range overlap. Methods in Ecology and Evolution, 9, 1679-1691. https://doi.org/10.1111/2041-210X.13027

Wrangham, R., Lundy, R., Crofoot, M., \& Gilby, I. (2007). Use of overlap zones among group-living primates: A test of the risk hypothesis. Behaviour, 144, 1599-1619. https://doi.org/10.1163/1568539077 82512092

Wrangham, R., Wilson, M., \& Hauser, M. (2007). Chimpanzees (Pan troglodytes) modify grouping and vocal behaviour in response to location-specific risk. Behaviour, 144, 1621-1653. https://doi. org/10.1163/156853907782512137

Wronski, T. (2005). Home-range overlap and spatial organization as indicators for territoriality among male bushbuck (Tragelaphus scriptus). Journal of Zoology, 266, 227-235. https://doi.org/10.1017/S0952 836905006825

Zimmermann, B., Nelson, L., Wabakken, P., Sand, H., \& Liberg, O. (2014). Behavioral responses of wolves to roads: Scale-dependent ambivalence. Behavioral Ecology, 25, 1353-1364. https://doi.org/10.1093/ beheco/aru134

\section{SUPPORTING INFORMATION}

Additional supporting information may be found online in the Supporting Information section.

How to cite this article: Noonan MJ, Martinez-Garcia R, Davis $\mathrm{GH}$, et al. Estimating encounter location distributions from animal tracking data. Methods Ecol Evol. 2021;12:11581173. https://doi.org/10.1111/2041-210X.13597 